\title{
Errata
}

doi:10.1093/pan/mpl004

\section{Toward a Pluralistic Vision of Methodology}

doi:10.1093/pan/mpj021

Henry E. Brady, David Collier, and Jason Seawright

Political Analysis 14(3):353-368.

The subtitle of the book on the third line of the introduction should have read Rethinking Social Inquiry: Diverse Tools, Shared Standards. 